\title{
The effect of triazolam premedication on anxiety, sedation, and amnesia in general anesthesia
}

\author{
Taehee Pyeon ${ }^{1}$, Shiyoung Chung ${ }^{1}$, Injae Kim², Seongheon Lee ${ }^{1}$, and \\ Seongwook Jeong ${ }^{1}$ \\ Departments of ${ }^{1}$ Anesthesiology and Pain Medicine, ${ }^{2}$ Molecular Medicine, Chonnam National University Medical \\ School, Gwangju, Korea
}

\begin{abstract}
Background: Benzodiazepines have been used preoperatively as part of an anesthesia regimen to attenuate the anxiety of patients. In this study, we aimed to examine the effect of oral triazolam, a short-acting benzodiazepine, on anxiety, sedation, and amnesia.

Methods: Ninety patients, aged 20-55 years, were randomly assigned to receive no premedication, or to receive triazolam $0.25 \mathrm{mg}$ or $0.375 \mathrm{mg} 1 \mathrm{~h}$ before anesthesia. Anxiety score, sedation score, blood pressure, heart rate and psychomotor performance were measured on the evening before surgery and on the day of surgery. Additional tests of psychomotor performance were performed in the postanesthesia care unit and on the next day of surgery. The occurrence of amnesia, bispectral index (BIS), recovery profiles and patient satisfaction with overall anesthesia care were also evaluated.

Results: Changes in the anxiety and sedation scores on the day of surgery were not significantly different among groups, whereas the increases in systolic blood pressure and heart rate were significantly less in both triazolam groups. The triazolam groups both showed a higher incidence of high satisfaction scores $(\geq 2)$. The two triazolam groups also showed similar outcomes, except for a dose-dependent increase in the number of patients with amnesia and BIS values $<90$. Delayed recovery from general anesthesia and psychomotor impairment were not observed in the triazolam groups.

Conclusions: Triazolam $0.25 \mathrm{mg}$ or $0.375 \mathrm{mg}$ reduced the hemodynamic changes associated with anxiety, produced potent amnesia, and improved patient satisfaction. We suggest that triazolam can be used effectively as anesthetic premedication in adults.
\end{abstract}

Key Words: Amnesia, Anxiety, Benzodiazepines, Premedication, Triazolam.

Corresponding author: Seongwook Jeong, M.D., Ph.D.

Department of Anesthesiology and Pain Medicine, Chonnam National University Medical School, 42, Jebong-ro, Dong-gu, Gwangju 61469, Korea

Tel: 82-62-220-6895, Fax: 82-62-232-6294

Email: anesman@gmail.com

ORCID: http://orcid.org/0000-0002-1958-8436

Received: May 15, 2016.

Revised: September 29, 2016 (1st); November 29, 2016 (2nd).

Accepted: December 8, 2016.

Korean J Anesthesiol 2017 June 70(3): 292-298

https://doi.org/10.4097/kjae.2017.70.3.292

\section{Introduction}

Most patients experience anxiety and stress before anesthesia and surgery [1]. Traditionally, benzodiazepine premedication has been used to prevent adverse effects from preoperative anxiety [2,3]. Recently, however, the use of benzodiazepines has declined in healthy adult patients. This could be due to concerns about potential oversedation before anesthesia, delayed recovery from anesthesia, and impairment of psychomotor function in the early postoperative period [4]. Nevertheless, anxiolysis with an adequate dose of benzodiazepine may lead to a more hemodynamically stable induction of anesthesia $[5,6]$ and improved general wellbeing of patients, and patient satisfaction [7].

(c) This is an open-access article distributed under the terms of the Creative Commons Attribution Non-Commercial License (http://creativecommons.org/ licenses/by-nc/4.0/), which permits unrestricted non-commercial use, distribution, and reproduction in any medium, provided the original work is properly cited. 
Midazolam is the most commonly administered benzodiazepine, especially via the oral route [8]; however, benzodiazepine as an oral tablet is not currently available in South Korea. Similar to midazolam, triazolam is a short-acting benzodiazepine that has been used in various clinical fields $[9,10]$. However, only a limited number of studies have examined the use of oral triazolam premedication before general anesthesia $[11,12]$. In our previous study compared the use of triazolam $0.25 \mathrm{mg}$ and alprazolam $0.5 \mathrm{mg}$ as oral premedications, no significant differences in anxiety or sedation were observed between the two groups, or in within-group analyses (before versus after premedication) [13]. We assumed that these neutral results might have been due to the lack of a comparable control group or insufficient drug dose, because triazolam is known to possess anxiolytic, sedative and amnesic properties that also characterize other benzodiazepines $[10,14]$.

Therefore, the present study included a no premedication group, as well as usual- and high- dose triazolam premedication groups. The primary endpoint was to clarify the effectiveness of triazolam premedication for adults, with respect to factors such as anxiety, sedation, and amnesia. We also evaluated the effects of triazolam on anesthetic recovery, psychomotor performance and patient satisfaction.

\section{Materials and Methods}

Ninety patients, of American Society of Anesthesiologists physical status classification I-II, who were aged 20-55 and were scheduled for elective surgery under general anesthesia, were enrolled. Patients who took analgesic, sedative, antidepressant, or antiepileptic drugs within the week before surgery were excluded. The study was approved by the Institutional Review Board of our institution and National Research Institute of Health (KCT0001720, https://cris.nih.go.kr/cris/en/).

On the evening prior to surgery, a routine preoperative visit was performed by the assigned anesthesiologist, with written informed consent for study participation and anesthesia obtained separately. A research nurse then evaluated the patient's baseline level of anxiety, sedation, psychomotor performance, and hemodynamic variables such as systolic blood pressure and heart rate. The level of anxiety was determined using a 7-point scale ( 0 , calm and relaxed; 1 , apprehension; 2 , mild anxiety with unsteady eyes; 3 , moderate anxiety with body shaking; 4 , verbally expressing anxiety without being asked; 5 , severe anxiety; and 6 , crying) $[13,15]$. The level of sedation was determined by a 5 -point scale ( 0 , alert; 1 , aroused by voices; 2 , aroused by gentle tactile stimulation; 3 , aroused by vigorous stimulation; and 4 , lack of responsiveness) [13]. Because psychomotor performance (visual-motor coordination) may be affected by the perioperative use of benzodiazepines, we evaluated it using a Digit Sym- bol Substitution Test (DSST) $[13,16]$. The DSST consists of digitsymbol pairs (e.g., $1 /-, 2 / \perp \ldots 7 / \Lambda, 8 / \mathrm{X}, 9 /=$ ) followed by a list of 20 digits. The patient was asked to write the corresponding symbol under each digit as fast as possible, and the completion time was recorded.

On the day of surgery, patients were allocated to receive no premedication (control group), or oral triazolam (Halcion ${ }^{\circledR}$; Pfizer, New York, NY, USA) 0.25 mg (T0.25 group) or $0.375 \mathrm{mg}$ (T0.375 group) according to a computer-generated randomization list. The study drug was administered $1 \mathrm{~h}$ before transfer to the operating room, because a plateau concentration of oral triazolam is achieved in $30 \mathrm{~min}$ and maintained for $180 \mathrm{~min}$ [17]. Upon patient arrival in the operating room, the same research nurse evaluated the patient's level of anxiety, sedation, psychomotor performance, and hemodynamic variables. In a memory test used to detect amnesia, the research nurse showed each patient an object, such as a stethoscope, while saying the name of object, and asked the patient to remember it [13]. Then, a bispectral index sensor $\left(\mathrm{BIS}^{\circledR}\right.$, Aspect Medical Systems, Norwood, MA, USA) was applied and patients were asked to keep their eyes closed. To confirm the accuracy of the measurement, a BIS value was obtained when the signal quality exceeded 50 . General anesthesia was induced with $2.0 \mathrm{mg} / \mathrm{kg}$ intravenous propofol, and endotracheal intubation was facilitated by rocuronium $0.8 \mathrm{mg} / \mathrm{kg}$. Anesthesia was maintained with desflurane (4-5 vol\%) and remifentanil to achieve BIS values between 40 and 60 . At the end of surgery, serotonin type 3 antagonists were given to the patient to prevent postoperative nausea and vomiting. Residual neuromuscular block was reversed with pyridostigmine and glycopyrrolate. After tracheal extubation, the patient was transported to the postanesthesia care unit (PACU), where consciousness scores were recorded every $15 \mathrm{~min}$ (0, unresponsive; 1 , aroused by calling; 2 , fully awake). The incidence of nausea and vomiting was recorded during the PACU stay. When the patient was ready for discharge, the PACU stay time was recorded and psychomotor performance was re-evaluated.

On the next day of surgery, the research nurse asked each patient whether he/she remembered being moved from the ward to the operating room and inquired about the object shown before anesthesia. When the patient could not remember either of these, amnesia was confirmed. The psychomotor performance and patient satisfaction score concerning overall anesthesia care (0, unsatisfactory; 1 , fair; 2 , good, 3 ; excellent) were also evaluated.

The sample size was calculated using data from a preliminary study, which suggested a 0.4 -fold difference in the proportion of patients with increased anxiety in the operating room between the no premedication and triazolam $0.25 \mathrm{mg}$ groups. For a twosided test of difference, using $\alpha=0.016$ (error type $\mathrm{I} /$ number of comparisons $=0.05 / 3$ ) and $\beta=0.2$ for each comparison, the 
required sample size was estimated to be 28 evaluable patients per group. Assuming a dropout rate of 5\%, we planned to recruit 30 patients to each group. Differences among the groups were assessed by one-way analysis of variance (ANOVA) or Student's t-test for normally distributed variables, by the Kruskal-Wallis test for non-normally distributed variables, and by Fisher's exact test or the linear-by-linear association test for categorical variables. The DSST completion times, as an index of psychomotor performance, were compared using repeated measures ANOVA. Spearman's correlation coefficients were calculated for all measured variables. SPSS for Windows software (ver. 20.0, IBM Corp., Armonk, NY, USA) was used for statistical analyses.
$P$ values less than 0.05 were considered statistically significant.

\section{Results}

The three groups were similar with respect to age, gender, weight, operation site, and duration of anesthesia (Table 1). Time intervals from medication to arrival in the operating room were also similar between both triazolam groups. In total, 15.6\% of patients (14 out of 90) were excluded due to patient refusal (n $=3)$, follow-up failure $(\mathrm{n}=4)$, randomization error $(\mathrm{n}=3)$, and an inadequate time interval from medication to arrival in the operating room $(n=4)$.

Table 1. Demographic Data

\begin{tabular}{|c|c|c|c|c|}
\hline & $\begin{array}{l}\text { Control } \\
(\mathrm{n}=24)\end{array}$ & $\begin{array}{c}\mathrm{T} 0.25 \\
(\mathrm{n}=25)\end{array}$ & $\begin{array}{c}\mathrm{T} 0.375 \\
(\mathrm{n}=27)\end{array}$ & $P$ value \\
\hline Age (yr) & $45.3 \pm 6.9$ & $42.7 \pm 9.7$ & $45.8 \pm 5.0$ & $0.289^{\mathrm{a}}$ \\
\hline Gender $(\mathrm{M} / \mathrm{F})$ & $9 / 15$ & $11 / 14$ & $11 / 16$ & $0.956^{\mathrm{b}}$ \\
\hline Weight (kg) & $64.6 \pm 6.8$ & $62.9 \pm 10.3$ & $67.0 \pm 7.3$ & $0.208^{\mathrm{a}}$ \\
\hline Operation site & & & & $0.866^{\mathrm{b}}$ \\
\hline Breast & 10 & 9 & 12 & \\
\hline Thyroid & 11 & 10 & 11 & \\
\hline Abdomen & 3 & 6 & 4 & \\
\hline Duration of anesthesia (min) & $119.8 \pm 36.0$ & $135.4 \pm 70.1$ & $112.9 \pm 44.7$ & $0.617^{\mathrm{c}}$ \\
\hline Time interval from medication to operating room ( $\mathrm{min}$ ) & - & $53.8 \pm 17.2$ & $50.1 \pm 13.0$ & $0.390^{\mathrm{d}}$ \\
\hline
\end{tabular}

Values are represented by means $\pm \mathrm{SD}$, or number of patients. T0.25: triazolam $0.25 \mathrm{mg}$, T0.375: triazolam $0.375 \mathrm{mg} .{ }^{\mathrm{a}}$ One-way analysis of variance, ${ }^{\mathrm{b}}$ Fisher's exact test, ${ }^{\mathrm{c}}$ Kruskal-Wallis test, ${ }^{\mathrm{d}}$ Student's t-test.

Table 2. Effects of Triazolam on Anxiety, Hemodynamics, Sedation, and Amnesia

\begin{tabular}{|c|c|c|c|c|}
\hline & $\begin{array}{l}\text { Control } \\
(\mathrm{n}=24)\end{array}$ & $\begin{array}{c}\mathrm{T} 0.25 \\
(\mathrm{n}=25)\end{array}$ & $\begin{array}{c}\mathrm{T} 0.375 \\
(\mathrm{n}=27)\end{array}$ & $P$ value \\
\hline \multicolumn{5}{|l|}{ Anxiety score } \\
\hline Baseline & $0.8 \pm 0.8$ & $0.8 \pm 0.6$ & $0.9 \pm 1.0$ & $0.852^{\mathrm{a}}$ \\
\hline In the operating room & $1.5 \pm 1.0$ & $0.8 \pm 0.6$ & $1.1 \pm 0.8$ & $0.053^{\mathrm{a}}$ \\
\hline Change from baseline & $0.8 \pm 1.2$ & $0.0 \pm 0.9$ & $0.1 \pm 1.3$ & $0.055^{\mathrm{a}}$ \\
\hline \multicolumn{5}{|l|}{ Systolic blood pressure $(\mathrm{mmHg})$} \\
\hline Baseline & $113.1 \pm 10.8$ & $118.2 \pm 12.4$ & $115.7 \pm 11.3$ & $0.187^{\mathrm{b}}$ \\
\hline In the operating room & $138.1 \pm 19.3$ & $128.4 \pm 13.3$ & $127.8 \pm 13.5$ & $0.091^{\mathrm{b}}$ \\
\hline Change from baseline & $24.0 \pm 19.0$ & $10.1 \pm 14.7^{*}$ & $12.2 \pm 12.4^{*}$ & $0.008^{b}$ \\
\hline \multicolumn{5}{|l|}{ Heart rate (beats/min) } \\
\hline Baseline & $71.5 \pm 7.5$ & $73.2 \pm 11.5$ & $72.9 \pm 9.8$ & $0.803^{\mathrm{b}}$ \\
\hline In the operating room & $79.8 \pm 13.3$ & $71.6 \pm 15.0$ & $69.2 \pm 11.1^{*}$ & $0.034^{\mathrm{b}}$ \\
\hline Change from baseline & $7.8 \pm 12.9$ & $-1.3 \pm 13.2^{*}$ & $-3.1 \pm 12.2^{*}$ & $0.008^{\mathrm{b}}$ \\
\hline \multicolumn{5}{|c|}{ Sedative score (baseline score $=0$ in all patients) } \\
\hline In the operating room & $0 \pm 0$ & $0.1 \pm 0.3$ & $0.2 \pm 0.4$ & $0.163^{\mathrm{a}}$ \\
\hline Presence of sedation $(\geq 1)$ & $0(0 \%)$ & $3(12.0 \%)$ & $4(14.8 \%)$ & $0.204^{\mathrm{c}}$ \\
\hline Bispectral index (BIS) & $94.5 \pm 4.7$ & $92.6 \pm 7.4$ & $91.2 \pm 7.5$ & $0.256^{\mathrm{a}}$ \\
\hline BIS $<90$ & $2(8.3 \%)^{\dagger}$ & $7(28.0 \%)^{\dagger}$ & $9(33.3 \%)^{\dagger}$ & $0.085^{c}, 0.039^{d}$ \\
\hline Amnesia & $0(0 \%)^{+}$ & $6(24.0 \%)^{*,+}$ & $10(37.0 \%)^{*,+}$ & $0.005^{c,} 0.001^{\mathrm{d}}$ \\
\hline
\end{tabular}

Values are represented by means $\pm \mathrm{SD}$, or number of patients (\%). Anxiety scores range from 0-6 (calm to crying). Sedative scores range from 0-4 (alert to unresponsive). Amnesia was confirmed on the next day of surgery. T0.25: triazolam $0.25 \mathrm{mg}$, T0.375: triazolam $0.375 \mathrm{mg}$. ${ }^{\mathrm{a}} \mathrm{Kruskal}-\mathrm{Wallis}$ test, one-way analysis of variance $\left({ }^{*} \mathrm{P}<0.05\right.$ vs. control group on post hoc Tukey's test), ${ }^{\mathrm{c}}$ Fisher's exact test, ${ }^{\mathrm{d}}$ linear-by-linear association $\left({ }^{\dagger} \mathrm{P}<0.05\right)$. 
Baseline anxiety score, systolic blood pressure and heart rate measured on the evening prior to surgery were similar among the groups (Table 2). Upon arrival in the operating room, the proportion of patients showing increased anxiety in the control, T0.25 and T0.375 groups was 58.3\% $(n=14), 32.0 \%(n=8)$, and $40.1 \%(\mathrm{n}=11)$, respectively; these differences were not statistically significant $(\mathrm{P}=0.167)$. The changes in anxiety scores from baseline were also not statistically different among the groups $(\mathrm{P}=0.055)$. However, systolic blood pressure and heart rate showed marked increases in the control group, whereas the corresponding increases were significantly lower in the T0.25 and T0.375 groups (Fig. 1).

Most patients were alert (sedation score $=0$ ), although seven patients in the triazolam groups were minimally sedated and aroused by voices (sedation score $=1$ ). The presence of sedation (sedation score $\geq 1$ ) and BIS values before anesthesia induc- tion were not significantly different among the groups (Table 2). However, there was a positive correlation between triazolam dose and the number of patients with BIS values $<90$ (linear-bylinear association, $\mathrm{P}=0.039$ ). The incidence of amnesia was also dose-dependent (linear-by-linear association, $\mathrm{P}=0.001$ ), and significantly higher in the T0.25 and T0.375 groups (Table 2). No patient showed amnesia in the control group. Except for the dose-dependent increase in the number of patients with amnesia and BIS values $<90$, there were no significant differences in outcomes between the T0.25 and T0.375 groups.

Delayed recovery from general anesthesia was not observed in any study group with respect to the time from end of surgery to PACU admission, PACU stay time, and consciousness scores in the PACU (Table 3). The rate of return to baseline psychomotor performance, as assessed by the DSST completion time was also similar among the groups. The incidence of nausea
A

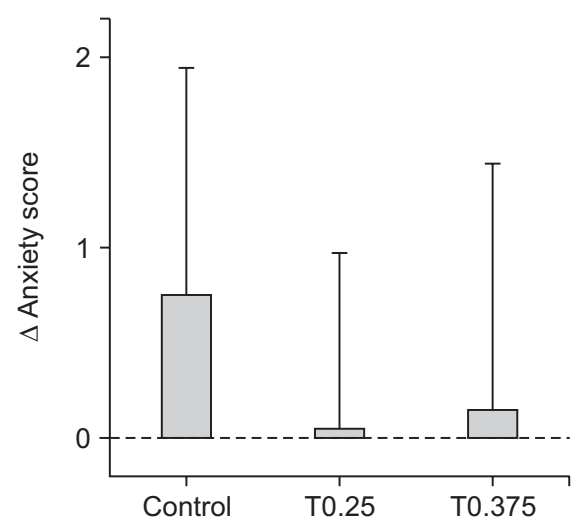

B

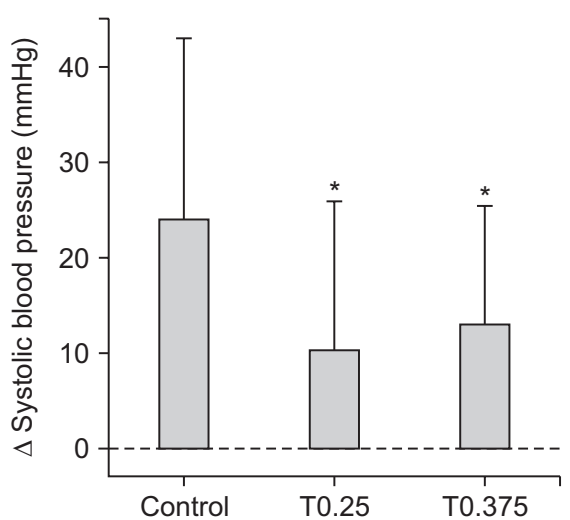

C

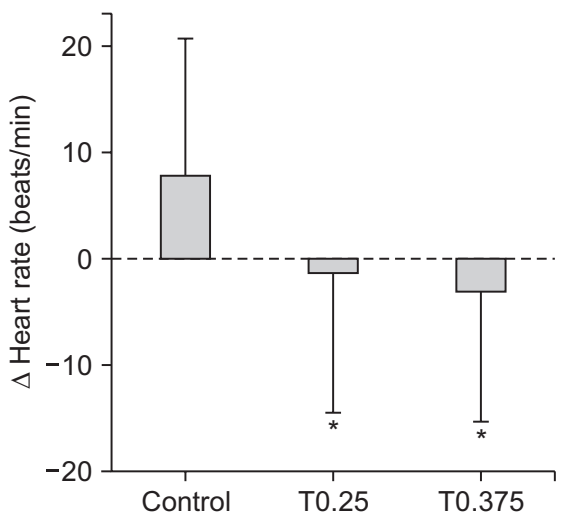

Fig. 1. The changes in anxiety score, systolic blood pressure and heart rate in the operating room compared with baseline values. ${ }^{*} \mathrm{P}<0.05 \mathrm{vs}$. control. T0.25: triazolam $0.25 \mathrm{mg}$, T0.375: triazolam $0.375 \mathrm{mg}$.

Table 3. Effects of Triazolam on Anesthetic Recovery

\begin{tabular}{|c|c|c|c|c|}
\hline & $\begin{array}{l}\text { Control } \\
(\mathrm{n}=24)\end{array}$ & $\begin{array}{c}\text { T0.25 } \\
(\mathrm{n}=25)\end{array}$ & $\begin{array}{c}\text { T0.375 } \\
(\mathrm{n}=27)\end{array}$ & $\mathrm{P}$ value \\
\hline Time from end of surgery to PACU (min) & $9.6 \pm 2.5$ & $10.4 \pm 1.4$ & $10.2 \pm 1.7$ & $0.312^{\mathrm{a}}$ \\
\hline PACU stay (min) & $53.5 \pm 10.4$ & $52.4 \pm 12.8$ & $55.6 \pm 10.5$ & $0.343^{\mathrm{a}}$ \\
\hline \multicolumn{5}{|l|}{ Consciousness scores in PACU } \\
\hline On arrival & $1.0 \pm 0.2$ & $1.2 \pm 0.4$ & $1.0 \pm 0.2$ & $0.083^{\mathrm{a}}$ \\
\hline Overall stay & $1.7 \pm 0.2$ & $1.7 \pm 0.2$ & $1.6 \pm 0.2$ & $0.616^{\mathrm{a}}$ \\
\hline DSST completion time (s) & & & & $0.217^{\mathrm{b}}$ \\
\hline Baseline & $39.3 \pm 10.7$ & $41.9 \pm 12.9$ & $44.0 \pm 12.5$ & \\
\hline In the operating room & $34.4 \pm 11.8$ & $41.5 \pm 15.6$ & $40.2 \pm 14.3$ & \\
\hline At PACU discharge & $51.6 \pm 25.7$ & $68.1 \pm 28.1$ & $67.2 \pm 27.9$ & \\
\hline On the next day of surgery & $31.6 \pm 10.1$ & $38.4 \pm 16.7$ & $35.5 \pm 15.9$ & \\
\hline Nausea in PACU & $4(16.7 \%)$ & $0(0 \%)$ & $1(3.7 \%)$ & $0.039^{c}$ \\
\hline Vomiting in PACU & $2(8.3 \%)$ & $0(0 \%)$ & $0(0 \%)$ & $0.097^{\mathrm{c}}$ \\
\hline
\end{tabular}

Values are represented by means \pm SD, or number of patients (\%). Consciousness score: 0 , unresponsive; 1 , arousable by voices; 2 , fully awake. PACU: postanesthesia care unit, DSST: Digit Symbol Substitution Test. T0.25: triazolam $0.25 \mathrm{mg}$, T0.375: triazolam $0.375 \mathrm{mg}$. ${ }^{\mathrm{a}} \mathrm{Kruskal}-\mathrm{Wallis}$ test, ${ }^{\mathrm{b}}$ repeated measures analysis of variance (group by time interaction), ${ }^{c}$ Fisher's exact test. 
Table 4. Patient Satisfaction with Overall Anesthesia Care

\begin{tabular}{ccccc}
\hline & $\begin{array}{c}\text { Control } \\
(\mathrm{n}=24)\end{array}$ & $\begin{array}{c}\text { T0.25 } \\
(\mathrm{n}=25)\end{array}$ & $\begin{array}{c}\text { T0.375 } \\
(\mathrm{n}=27)\end{array}$ & P value \\
\hline Patient satisfaction score & $1.7 \pm 1.2$ & $2.4 \pm 0.8$ & $2.4 \pm 0.6$ & $0.054^{\mathrm{a}}$ \\
Score $=3$ & $10(41.7 \%)$ & $13(52.0 \%)$ & $14(51.9 \%)$ & $0.741^{\mathrm{b}}, 0.479^{\mathrm{c}}$ \\
Score $\geq 2$ & $11(45.8 \%)^{\dagger}$ & $21(84.0 \%)^{*,+}$ & $25(92.6 \%)^{*,+}$ & $<0.001^{\mathrm{b}, \mathrm{c}}$ \\
Score $\geq 1$ & $19(79.2 \%)^{\dagger}$ & $25(100 \%)^{\dagger}$ & $27(100 \%)^{\dagger}$ & $0.002^{\mathrm{b}}, 0.004^{\mathrm{c}}$ \\
\hline
\end{tabular}

Values are represented by means \pm SD, or number of patients (\%). Patient satisfaction scores range from $0-3$ (unsatisfactory to excellent). T0.25: triazolam $0.25 \mathrm{mg}$, T0.375: triazolam $0.375 \mathrm{mg}$. ${ }^{a}$ Kruskal-Wallis test, ${ }^{\mathrm{b}}$ Fisher's exact test $\left({ }^{*} \mathrm{P}<0.017 \mathrm{vs}\right.$. control group in pairwise analysis), ${ }^{c}$ linear-bylinear association $\left({ }^{\dagger} \mathrm{P}<0.05\right)$.

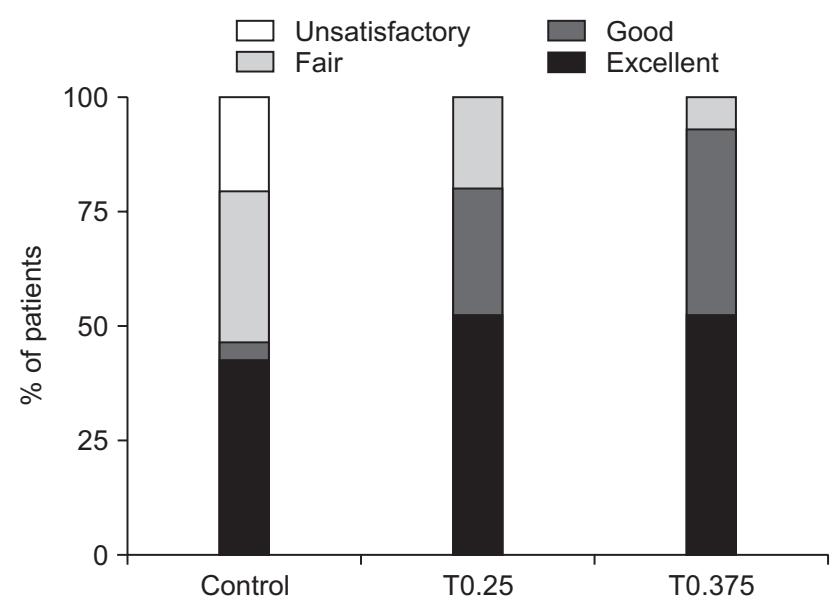

Fig. 2. Distribution of patient satisfaction by group. T0.25: triazolam 0.25 mg, T0.375: triazolam $0.375 \mathrm{mg}$.

was $16.7 \%$ in the control group compared with $0 \%$ in the T0.25 group and $3.7 \%$ in the $\mathrm{T} 0.375$ group $(\mathrm{P}=0.039)$; however, post hoc analysis with Bonferroni correction did not reach statistical significance. In all patients, no respiratory depression was observed in the preoperative or postoperative period.

Regarding patient satisfaction scores for overall anesthesia care, the mean scores were not significantly different among the groups, although the T0.25 and T0.375 groups showed a significantly higher incidence of high scores $(\geq 2)$ compared with the control group (Table 4, Fig. 2). Satisfaction scores were also correlated with the presence of sedation $(\geq 1)$, as well as with the number of patients with a BIS value $<90$ and amnesia $(\mathrm{P}<0.05$, Spearman correlation coefficient $=0.243,0.227$ and 0.228 , respectively) (Fig. 3).

\section{Discussion}

This clinical study evaluated the effect of oral triazolam premedication at $0.25 \mathrm{mg}$ and $0.375 \mathrm{mg}$ on anxiety, sedation, and amnesia in adults undergoing general anesthesia. Previous studies have demonstrated that triazolam at $0.25 \mathrm{mg}$ has significant anxiolytic and sedative effects [11,18]. In contrast, Baughman

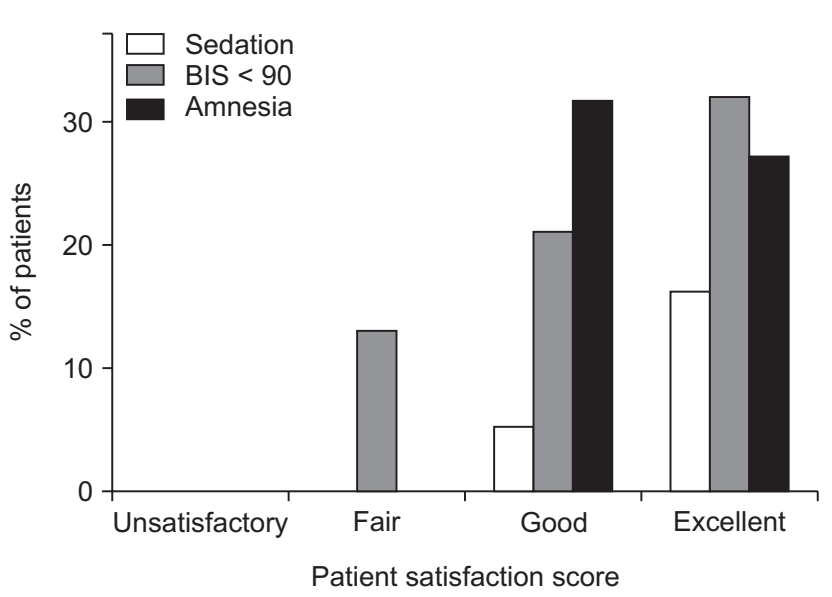

Fig. 3. Proportion of patients with sedation, bispectral index (BIS) $<90$ and amnesia by patient satisfaction level. Sedation $=$ sedative score $\geq 1$.

et al. [12] reported that those effects were significant only at $0.5 \mathrm{mg}$. However, Longbottom and Pleuvry [19] showed that triazolam at $0.5 \mathrm{mg}$ produced significantly prolonged cognitive deficits, despite a better sedative effect compared with $0.25 \mathrm{mg}$. Therefore, we selected the usual recommended dose of 0.25 $\mathrm{mg}$, as well as a slightly higher dose of $0.375 \mathrm{mg}$, rather than the maximum permissible dose of $0.5 \mathrm{mg}$ to reduce unnecessary complications.

In the present study, both triazolam $0.25 \mathrm{mg}$ and $0.375 \mathrm{mg}$ significantly lessened the increase of systolic blood pressure and heart rate before anesthesia induction. Since such hemodynamic changes have been used as physiologic indicators of anxiety response [20,21], this finding suggests that triazolam has a clinically meaningful anxiolytic effect. In terms of the anxiety score, the level of anxiety in both triazolam groups was generally lower than that in the control group, although the differences were not statistically significant.

Numerous studies have demonstrated a significant sedative effect of triazolam $[11,18]$. In the present study, however, the sedative effects of triazolam at $0.25 \mathrm{mg}$ and $0.375 \mathrm{mg}$ were not prominent in either the subjective (sedation scale) or objective (BIS) assessments. These results correlated with those of our 
previous study [13], which showed that sedation level did not increase significantly from baseline in the triazolam $0.25 \mathrm{mg}$ group. Baughman et al. [12] also reported that only triazolam at $0.5 \mathrm{mg}$, and not at $0.25 \mathrm{mg}$ or $0.125 \mathrm{mg}$, produced more sedation than placebo. Taken together, although a dose-dependent increase in the number of patients with BIS values $<90$ was observed in the present study, it is likely that triazolam at below 0.5 $\mathrm{mg}$ has a weak sedative effect in adult patients.

Meanwhile, the amnesic effect of triazolam $0.25 \mathrm{mg}$ and 0.375 mg was strong and significant, consistent with previous studies $[11,13]$; it was also dose-dependent. This high amnesic potential could be helpful for patients who have unpleasant memories of the operating room before anesthetic induction $[22,23]$. The correlation analysis in the present study showed that patients who had amnesia, or even weak sedation, tended to report higher levels of satisfaction with overall anesthesia care.

No significant delay in postoperative mental or psychomotor recovery was observed among the healthy young adults included in the present study. However, in elderly populations, and in patients with hepatic dysfunction, greater and prolonged sedation or impairment of psychomotor function could occur due to high plasma concentrations and high sensitivity to triazolam [24,25]. Therefore, triazolam should be used cautiously, and with dose adjustment, in such populations.

One interesting finding was that postoperative nausea was less common in the triazolam groups compared with the control group, although the difference did not reach statistical significance. Numerous studies, and a recent meta-analysis including 12 randomized controlled trials, have highlighted the antiemetic properties of benzodiazepines, particularly midazolam, when used in the perioperative period [26,27]. Further studies with larger sample sizes and longer follow-ups will be necessary to confirm this potential advantage of triazolam premedication.

The present study had some limitations. First, we compared $0.25 \mathrm{mg}$ and $0.375 \mathrm{mg}$ of triazolam in relatively healthy young adults. To ensure safe and effective use, the effect of various doses in a wide range of populations should be evaluated in future studies. Second, overall anxiety scores in the operating room were low, even in the control group $(1.5 \pm 1.0$ on a 7 -point scale). This finding may be explained by the anesthesiologist's preoperative visit as a routine practice in our hospital, which has been shown to reduce preoperative anxiety as effectively as pharmacologic intervention [28,29]. Therefore, the anxiolytic effect of triazolam may have been masked by the anxiolytic effect of a preoperative visit; this should be considered by future studies.

In conclusion, triazolam $0.25 \mathrm{mg}$ or $0.375 \mathrm{mg}$ significantly reduced the hemodynamic changes associated with anxiety, produced potent amnesia, and improved patient satisfaction with respect to overall anesthesia care. These favorable effects were not accompanied by oversedation or delayed recovery from general anesthesia. Therefore, we suggest that triazolam can be effective as an anesthetic premedication in adults, especially in countries where oral midazolam is not available.

\section{ORCID}

Taehee Pyeon, http://orcid.org/0000-0002-0749-7780

Injae Kim, http://orcid.org/0000-0002-7483-8469

Seongheon Lee, http://orcid.org/0000-0002-2675-2521

Seongwook Jeong, http://orcid.org/0000-0002-1958-8436

\section{References}

1. Mavridou P, Dimitriou V, Manataki A, Arnaoutoglou E, Papadopoulos G. Patient's anxiety and fear of anesthesia: effect of gender, age, education, and previous experience of anesthesia. A survey of 400 patients. J Anesth 2013; 27: 104-8.

2. Johnston M. Pre-operative emotional states and post-operative recovery. Adv Psychosom Med 1986; 15: 1-22.

3. Kain ZN, Sevarino F, Pincus S, Alexander GM, Wang SM, Ayoub C, et al. Attenuation of the preoperative stress response with midazolam: effects on postoperative outcomes. Anesthesiology 2000; 93: 141-7.

4. Sheen MJ, Chang FL, Ho ST. Anesthetic premedication: new horizons of an old practice. Acta Anaesthesiol Taiwan 2014; 52: 134-42.

5. Dionne RA, Goldstein DS, Wirdzek PR. Effects of diazepam premedication and epinephrine-containing local anesthetic on cardiovascular and plasma catecholamine responses to oral surgery. Anesth Analg 1984; 63: 640-6.

6. Abdul-Latif MS, Putland AJ, McCluskey A, Meadows DP, Remington SA. Oral midazolam premedication for day case breast surgery, a randomised prospective double-blind placebo-controlled study. Anaesthesia 2001; 56: 990-4.

7. Bauer KP, Dom PM, Ramirez AM, O'Flaherty JE. Preoperative intravenous midazolam: benefits beyond anxiolysis. J Clin Anesth 2004; 16: 177-83.

8. Kain ZN, Mayes LC, Bell C, Weisman S, Hofstadter MB, Rimar S. Premedication in the United States: a status report. Anesth Analg 1997; 84: 427-32.

9. Stopperich PS, Moore PA, Finder RL, McGirl BE, Weyant RJ. Oral triazolam pretreatment for intravenous sedation. Anesth Prog 1993; 40: 117-21.

10. Lieblich SE, Horswell B. Attenuation of anxiety in ambulatory oral surgery patients with oral triazolam. J Oral Maxillofac Surg 1991; 49: 
$792-6$.

11. Pinnock CA, Fell D, Hunt PC, Miller R, Smith G. A comparison of triazolam and diazepam as premedication agents for minor gynaecological surgery. Anaesthesia 1985; 40: 324-8.

12. Baughman VL, Becker GL, Ryan CM, Glaser M, Abenstein JP. Effectiveness of triazolam, diazepam, and placebo as preanesthetic medications. Anesthesiology 1989; 71: 196-200.

13. Kim D, Lee S, Pyeon T, Jeong S. Use of triazolam and alprazolam as premedication for general anesthesia. Korean J Anesthesiol 2015; 68: 346-51.

14. Mandrioli R, Mercolini L, Raggi MA. Benzodiazepine metabolism: an analytical perspective. Curr Drug Metab 2008; 9: 827-44.

15. Zaider TI, Heimberg RG, Fresco DM, Schneier FR, Liebowitz MR. Evaluation of the clinical global impression scale among individuals with social anxiety disorder. Psychol Med 2003; 33: 611-22.

16. Hindmarch I. Psychomotor function and psychoactive drugs. 1980. Br J Clin Pharmacol 2004; 58: S720-40.

17. Eberts FS Jr, Philopoulos Y, Reineke LM, Vliek RW. Triazolam disposition. Clin Pharmacol Ther 1981; 29: 81-93.

18. Ehrich DG, Lundgren JP, Dionne RA, Nicoll BK, Hutter JW. Comparison of triazolam, diazepam, and placebo as outpatient oral premedication for endodontic patients. J Endod 1997; 23: 181-4.

19. Longbottom RT, Pleuvry BJ. Respiratory and sedative effects of triazolam in volunteers. Br J Anaesth 1984; 56: 179-85.

20. Scheinin M, Scheinin H, Ekblad U, Kanto J. Biological correlates of mental stress related to anticipated caesarean section. Acta Anaesthesiol Scand 1990; 34: 640-4.

21. Gras S, Servin F, Bedairia E, Montravers P, Desmonts JM, Longrois D, et al. The effect of preoperative heart rate and anxiety on the propofol dose required for loss of consciousness. Anesth Analg 2010; 110: 89-93.

22. Chen XK, Zhou YP, Zhang X, Xia LP, Li AF, Liu H, et al. Conscious sedation with midazolam and dezocine for diagnostic flexible bronchoscopy. Eur Rev Med Pharmacol Sci 2015; 19: 3688-92.

23. Maltais F, Laberge F, Laviolette M. A randomized, double-blind, placebo-controlled study of lorazepam as premedication for bronchoscopy. Chest 1996; 109: 1195-8.

24. Greenblatt DJ, Harmatz JS, Shapiro L, Engelhardt N, Gouthro TA, Shader RI. Sensitivity to triazolam in the elderly. N Engl J Med 1991; 324: 1691-8.

25. Bakti G, Fisch HU, Karlaganis G, Minder C, Bircher J. Mechanism of the excessive sedative response of cirrhotics to benzodiazepines: model experiments with triazolam. Hepatology 1987; 7: 629-38.

26. Grant MC, Kim J, Page AJ, Hobson D, Wick E, Wu CL. The effect of intravenous midazolam on postoperative nausea and vomiting: a metaanalysis. Anesth Analg 2016; 122: 656-63.

27. Khalil SN, Berry JM, Howard G, Lawson K, Hanis C, Mazow ML, et al. The antiemetic effect of lorazepam after outpatient strabismus surgery in children. Anesthesiology 1992; 77: 915-9.

28. Egbert LD, Battit G, Turndorf H, Beecher HK. The value of the preoperative visit by an anesthetist. A study of doctor-patient rapport. JAMA 1963; 185: 553-5.

29. Arellano R, Cruise C, Chung F. Timing of the anesthetist's preoperative outpatient interview. Anesth Analg 1989; 68: 645-8. 